\title{
Low dose Flaxseed Oil Supplementation Alters the Fatty Acids Profile and the Progression of Metabolic Syndrome in Men without Adequate Medical Treatment
}

\section{Tint $D^{1}$, Anghel $\mathbf{M}^{1}$, Lupu $\mathrm{DS}^{2}$, Fischer $\mathrm{LM}^{3}$ and Niculescu MD ${ }^{2,3 *}$}

${ }^{1}$ School of Medicine, Transilvania University in Brasov, Brasov, Romania

${ }^{2}$ UNC Nutrition Research Institute, Kannapolis, NC, USA

${ }^{3}$ Department of Nutrition, School of Public Health, University of North Carolina at Chapel Hill, Chapel Hill, NC, USA

\begin{abstract}
Many studies indicated that increased intakes of $\omega-3$ fatty acids could positively impact the progression of metabolic syndrome (MS). This study aimed to characterize the clinical and biochemical changes initiated by a low-dose flaxseed oil supplementation upon the evolution of metabolic syndrome in men without adequate medical treatment.

In a double blind, randomized study, middle-aged men with metabolic syndrome, who were not able to follow the prescribed medical treatment, were assigned to either a group receiving daily $2.4 \mathrm{~g}$ flaxseed oil, or the same amount of corn oil, for 90 days, respectively. Analysis of variance, logistic, and bivariate fit analyses were used to describe the statistical significance of parameters changed by either treatment (within and between group comparisons), between the start and end of treatment. While none of the five diagnostic criteria for MS were differently altered between groups and time points, changes in body mass index (BMI) and insulin resistance were significantly correlated with the treatment received. Subjects receiving flaxseed oil registered no increase in BMI, as compared to an increased $\mathrm{BMI}$ registered in the corn oil group $(+1.12 \pm 0.63, p<0.05)$. Bivariate fit for plasma insulin and derived HOMA index indicated that flaxseed oil maintained the individual correlation of these parameters between the start and end of study, while corn oil supplementation was associated with an increase in insulin resistance with no individual correlation between start and end of treatment $(1.12 \pm 0.17, p<0.05$ vs. $2.11 \pm 0.79, p>0.05$ ratios between start and end of study, respectively).
\end{abstract}

The analysis of total serum fatty acid profiles indicated, among other changes, significance for time-treatment interaction for serum 11-eicosenoic acid $(p<0.05)$. Other correlations on inflammation markers associated with MS are reported. In conclusion, low daily doses of flaxseed oil may improve clinical and metabolic parameters in middle-aged men without adequate treatment for metabolic syndrome.

Keywords: Metabolic syndrome; Flaxseed oil; Body weight; Insulin resistance

\section{Introduction}

Metabolic syndrome (MS) is a common metabolic disorder with increasing prevalence all over the world [1]. MS is directly correlated with the development of obesity, and represents a major contributor in the development of cardiovascular diseases and type II diabetes [2]. Moreover, there is a significant overlap between MS and conditions such as polycystic ovarian syndrome, non-alcoholic fatty liver disease, hypogonadism, lipodystrophy, and microvascular disease [1]. The treatment of MS is complex and includes both lifestyle changes (physical activity and nutrition) and drug therapy [3]. However, while the drug therapy is relatively accessible in developed countries, MS patients in underdeveloped and developing countries often do not have adequate access to medical care, or their poor socio-economic status does not allow them to purchase and follow the prescribed medication [4].

Human and animal studies indicated that increased dietary intakes or supplementation with marine or plant derived $\omega-3$ fatty acids are inversely correlated with the presence of MS [5]. While the benefits of $\omega-3$ fatty acids have been amply supported by numerous studies, their mechanism of action is not completely understood, nor has a definitive answer been given regarding the dietary intakes necessary to attain such protective effects [6]. Polyunsaturated n-3 fatty acids may improve defects in insulin signaling, and prevent alterations in glucose homeostasis and the further development of type II diabetes [78]. Diets rich in $a$-linolenic acid (ALA) also appear to be beneficial in secondary cardiovascular prevention [9]. However, there is conflicting evidence regarding the specific role of ALA, eicosapentaenoic (EPA), and docosahexaenoic (DHA) acids on decreasing insulin resistance, and regarding their influence on inflammatory cytokine modulation. [10].

The aim of this study was to determine the consequences that lowdose supplementation with flaxseed oil may have upon clinical and biochemical outcomes in subjects with MS who did not receive proper medical treatment.

\section{Materials and Methods}

The study was performed according to the Declaration of Helsinki and approved by the Institutional Review Board at the University of North Carolina at Chapel Hill, and by the Ethics Committee at Transilvania University. Written consent was obtained from all participants before study initiation.

*Corresponding author: Niculescu MD, Rm. 2104, 500 Laureate Way, Kannapolis NC 28027, USA, Tel: +1 (704) 250 5029; Fax: +1 (704) 250 5001; E-mail: Mihai Niculescu@unc.edu

Received September 09, 2011; Accepted October 18, 2011; Published October 20, 2011

Citation: Tint D, Anghel M, Lupu DS, Fischer LM, Niculescu MD (2011) Low dose Flaxseed Oil Supplementation Alters the Fatty Acids Profile and the Progression of Metabolic Syndrome in Men without Adequate Medical Treatment. J Nutr Disorders Ther S7:001. doi:10.4172/2161-0509.S7-001

Copyright: (c) 2011 Tint D, et al. This is an open-access article distributed under the terms of the Creative Commons Attribution License, which permits unrestricted use, distribution, and reproduction in any medium, provided the original author and source are credited. 
Citation: Tint D, Anghel M, Lupu DS, Fischer LM, Niculescu MD (2011) Low dose Flaxseed Oil Supplementation Alters the Fatty Acids Profile and the Progression of Metabolic Syndrome in Men without Adequate Medical Treatment. J Nutr Disorders Ther S7:001. doi:10.4172/2161-0509. S7-001

Page 2 of 8

\section{Study population}

The study was a double-blind, controlled, randomized intervention trial in 20 male volunteer subjects, between 50-65 years of age, with diagnosed MS, recruited from Romania (Brasov area) between August 2008 and September 2009. MS was assessed according to the National Cholesterol Education Program's Adult Treatment Panel III report criteria (ATP III), for the presence of three or more of the following criteria: 1) waist circumference $\geq 40$ inches $(102 \mathrm{~cm}), 2)$ triglycerides (TG) $\geq 150 \mathrm{mg} / \mathrm{dl}, 3$ ) HDL-cholesterol $\leq 40 \mathrm{mg} / \mathrm{dl}$, 4) blood pressure (BP, systolic/diastolic) $\geq 130 / \geq 85 \mathrm{mmHg}$ or antihypertensive treatment, and 5) fasting glucose (FG) $\geq 110 \mathrm{mg} / \mathrm{dl}$ or antidiabetic medication (insulin or oral agents) [11].

Exclusion criteria consisted of: 1) any coagulation syndrome and/ or diagnosed blood disorder related to the number, morphological features, or physiology of red blood cells (RBC), white blood cells (WBC), or platelets, 2) family history of hereditary blood disorder, even in the absence of a diagnosed blood disorder, any carrier of a diagnosed genotype known to primarily cause a blood disorder, 3) history or presence of an embolic event (any organ), stroke, transient ischemic attack (TIA), ischemic heart disease, myocardial infarction, unstable angina, or varicose veins, 4) current use of a treatment or dietary supplements (for the past three months) containing any omega-3 fatty acid or any lipid modifying agent (e.g. statins, fibrates, ezetrol), and 5) any treatment including the administration of aspirin, ticlopidine/clopidogrel, non-steroidal anti-inflammatory drugs, and other hypocoagulant medication before and during the study.

\section{Study design}

Upon enrollment, the Brasov team assigned a number (from 1 to 20) to each enrolled subject. Following enrollment, the Chapel Hill team randomly assigned each of the subjects to either a group receiving corn oil ( $\mathrm{C}$ group, $\mathrm{n}=10$ ), or to a group receiving flaxseed oil ( $\mathrm{F}$ group, $\mathrm{n}=10$ ). Due to the small number of subjects, stratification prior to randomization was done only for BMI and age. The characteristics of subjects assigned to each group are presented in Table 1. Identical containers containing capsules with either $1.2 \mathrm{~g}$ of either corn oil or flaxseed oil were numbered by the Chapel Hill team according to each subject's assigned number, and shipped to Brasov. The lipid content of corn oil and flaxseed oil capsules is indicated in Table 2. The local team was blinded against both the content of capsules and group assignment. Each subject was instructed to consume two capsules a day for 90 days, and to not eat any food or take dietary supplements containing significant amounts of omega- 3 fatty acids (fish, seeds, nuts, etc.). Compliance was calculated based on the formula: number capsules taken/number capsules needed to be taken x 100. Compliance over $80 \%$ was targeted and achieved in both groups.

\section{Measurements}

Clinical and biochemical investigations were assessed on days 0 (D0, one day before the beginning of supplementation) and 90 (D90, end of study) for each subject. Safety monitoring visits were performed monthly during this period and consisted of clinical examination, blood pressure measurements, distribution of capsules for the next month, and evaluation of compliance. At D0 and D90, clinical evaluation included anthropometric and blood pressure measurements. Anthropometric measurements were performed under a fasting state with subjects wearing light clothing and no shoes. The waist circumference was measured at the high point of the iliac crest at minimal respiration to the nearest $0.1 \mathrm{~cm}$. BMI was calculated as $\mathrm{kg} / \mathrm{m}^{2}$.

For each study day, blood samples were collected by venipuncture in the morning following an overnight fast, using both $8 \mathrm{~mL} \mathrm{CPT}$ tubes and $8 \mathrm{~mL}$ tubes with heparin. Mononucleate cells were obtained using the CPT tubes, stored in RNA stabilization reagent (RNAlater, Qiagen, Germany) and shipped to Chapel Hill for further assessment. Plasma was obtained using heparinized tubes and used for subsequent determinations, or shipped to Chapel Hill for fatty acids measurements. In addition, serum was obtained from tubes without anticoagulant. Biochemical measurements (Table 3) included red blood cells (RBC), white blood cells (WBC) and platelet count, fasting glucose, and lipid measurements (total cholesterol (TC), HDLcholesterol (HDL-C), LDL-cholesterol (LDL-C), triglycerides (TG)), hepatic (Aspartate transaminase, AST; Alanine transaminase, ALT; total plasma proteins) and renal function (creatinine, urea), using reagents and kits from Roche Diagnostics (Manheim, Germany). Coagulation factors (international normalized ratio, INR; activated partial thromboplastin time, APTT, Instrumentation Laboratory SpA, Milano, Italy) were assessed during the same day. Serum for biochemical measurement of insulin, inflammatory markers (high sensitivity C-reactive protein CRP, IL6, IL1 $\beta$, TNF- $\alpha$ ), was frozen and stored at $-20^{\circ} \mathrm{C}$ and eventually analyzed using ELISA kits (insulin EIA1825, CRP HS EIA-3954, TNF- $\alpha$ EIA-4774, IL6 EIA-1869, IL10 EIA 0773 from DRG Instruments GmbH, Germany, IL1 $\beta$ EL10028 from Bio Supply, UK). Apolipoprotein A1 (ApoA1) and apolipoprotein B $(\mathrm{ApoB})$ were assessed based on immunoturbidimetric tests (DiaSys Diagnostic Systems GmbH, Holzheim, Germany).

\begin{tabular}{|l|l|l|l|}
\hline PARAMETER & C group & F group & P value \\
\hline Age & $54.80 \pm 1.98$ & $57.10 \pm 1.26$ & NS \\
\hline BMl & $30.92 \pm 1.95$ & $29.64 \pm 0.84$ & NS \\
\hline Waist & $117.00 \pm 4.49$ & $111.45 \pm 1.48$ & NS \\
\hline SBP $(\mathrm{mm} \mathrm{Hg})$ & $145.50 \pm 5.13$ & $149.00 \pm 6.22$ & NS \\
\hline DBP $(\mathrm{mm} \mathrm{Hg})$ & $90.00 \pm 3.07$ & $90.50 \pm 2.83$ & NS \\
\hline Glucose $(\mathrm{mg} / \mathrm{dl})$ & $126.00 \pm 11.00$ & $127.00 \pm 19.00$ & NS \\
\hline HDL-cholesterol $(\mathrm{mg} / \mathrm{dl})$ & $56.78 \pm 2.49$ & $44.78 \pm 3.37$ & $<0.05$ \\
\hline Triglycerides & $166.50 \pm 25.56$ & $220.40 \pm 20.57$ & NS \\
\hline
\end{tabular}

Clinical and biochemical measurements were performed at the beginning of the study, after group randomization (group means \pm standard error). C group, the group assigned to corn oil supplementation; $\mathrm{F}$ group, the group assigned to flaxseed oil supplementation; BMI, body mass index; SBP, systolic blood pressure; DBP, diastolic blood pressure. Statistical significance was determined using Student's t-test for $p<0.05$. NS, no significance.

Table 1: Baseline Measurements.

\begin{tabular}{|l|l|l|l|}
\hline \multicolumn{2}{|l|}{ FA species } & \multicolumn{3}{l|}{ FA concentration $\mu \mathrm{mol} / \mathrm{mL}$} \\
\cline { 4 - 5 } & Corn oil & Flaxseed oil \\
\hline $14: 0$ & myristic & ND & 1.26 \\
\hline $16: 0$ & palmitic & 368.51 & 200.44 \\
\hline $16: 1 \mathrm{n} 7$ & palmitoleic & 3.78 & 3.26 \\
\hline $18: 0$ & stearic & 55.47 & 119.01 \\
\hline $18: 1 \mathrm{n} 9$ & oleic & 844.36 & 528.58 \\
\hline $18: 2 \mathrm{n} 6$ & linoleic & 1653.74 & 554.79 \\
\hline $18: 3 \mathrm{n} 3$ & linolenic & 13.51 & 1638.40 \\
\hline $20: 0$ & eicosanoic & 25.24 & ND \\
\hline $20: 1 \mathrm{n} 9$ & 11 -eicosenoic & 9.31 & 5.79 \\
\hline $20: 2 \mathrm{n} 6$ & 11,14 -eicosadienoic & ND & 1.27 \\
\hline $20: 3 \mathrm{n} 3$ & $11,14,17-$-eicosatrienoic & ND & 1.53 \\
\hline $22: 0$ & behenic & 3.62 & 3.93 \\
\hline $22: 1 \mathrm{n} 9$ & erucic & ND & 1.28 \\
\hline $22: 5 \mathrm{n} 3$ & $7,10,13,16,19-d o c o s a p e n t a e n o i c$ & 1.66 & 1.06 \\
\hline $24: 0$ & lignoceric & 5.42 & 3.69 \\
\hline
\end{tabular}

ND, not detectable

Table 2: Fatty acid composition of supplements. 
Citation: Tint D, Anghel M, Lupu DS, Fischer LM, Niculescu MD (2011) Low dose Flaxseed Oil Supplementation Alters the Fatty Acids Profile and the Progression of Metabolic Syndrome in Men without Adequate Medical Treatment. J Nutr Disorders Ther S7:001. doi:10.4172/2161-0509. S7-001

Page 3 of 8

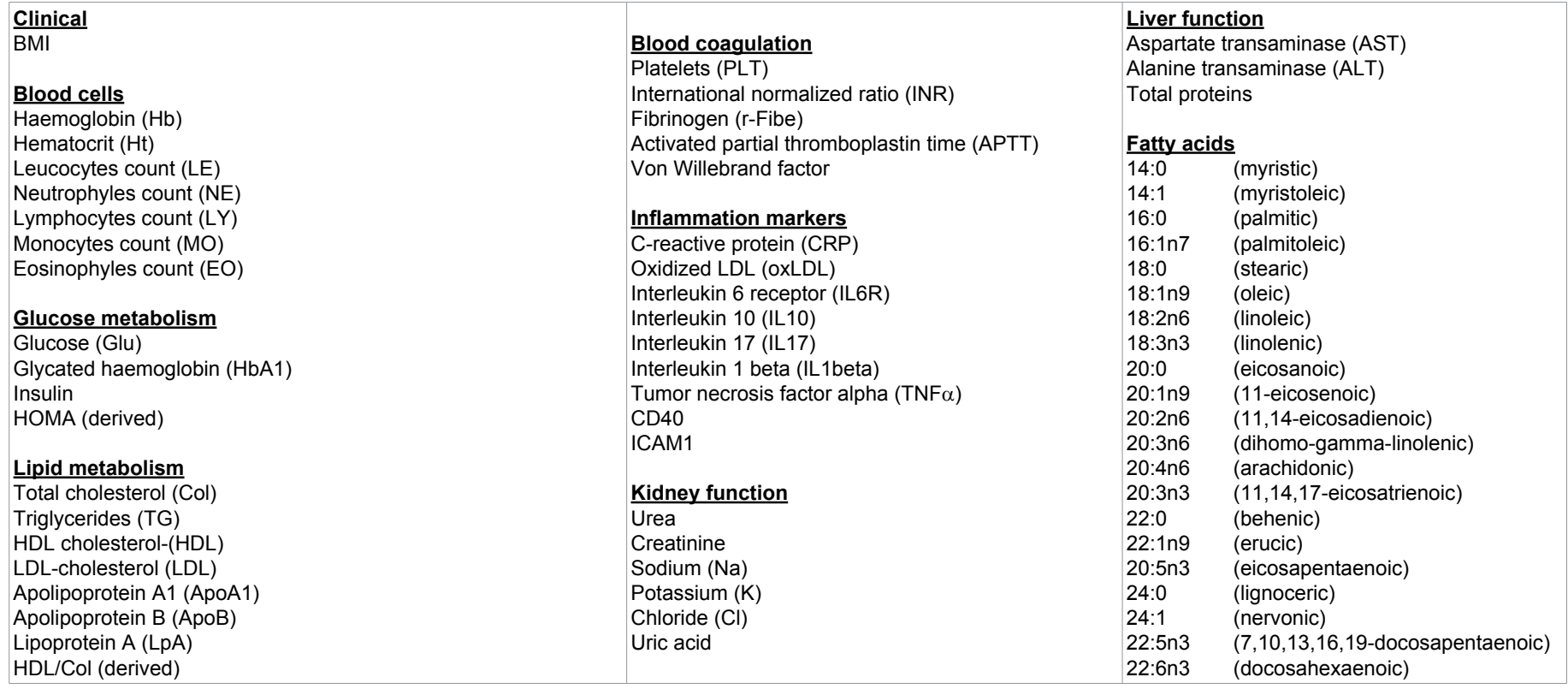

Table 3: Parameters measured at the beginning and end of study.

Platelet count and coagulation factors were assessed at inclusion and at the end of the study for safety reasons, due to the possible antithrombotic activity, reduced platelets aggregability and substantial increase of bleeding time after 3 months of flaxseed administration, as previously reported $[12,13]$. However, no such adverse events were reported in our study.

Insulin resistance was calculated using the HOMA-IR index, which derives an estimate of whole-body insulin sensitivity from fasting glucose and insulin concentrations: glucose $(\mathrm{mg} / \mathrm{dL}) \mathrm{x}$ insulin $(\mu \mathrm{U} /$ $\mathrm{mL}) / 405$ [14].

Total lipids from capsules and plasma $(200 \mu \mathrm{l})$ were extracted using the method of Bligh and Dyer at the UNC Nutritional Biochemistry and Molecular Biology Core. The lower (chloroform) phase was transferred to a clean tube and evaporated to dryness under nitrogen. The residual lipids were saponified and the fatty acids trans-methylated by sequential $1 \mathrm{ml}$ addition of $4.25 \% \mathrm{NaOH}$ in $\mathrm{CHCl}_{3}: \mathrm{MeOH}(2: 1$, $\mathrm{v} / \mathrm{v})$ and $1 \mathrm{~N} \mathrm{HCl}$ in saline [16]. The samples were mixed vigorously then centrifuged at $1500 \mathrm{rcf}$ for 5 minutes. The lower phase containing the fatty acid methyl esters was carefully transferred to a clean, dry tube and evaporated to dryness under nitrogen. Fatty acid methyl esters were then resuspended in $50 \mu \mathrm{l}$ undecane, and analyzed using capillary gas chromatography (GC) on a Perkin Elmer AutoSystem XL Gas Chromatograph (Shelton, CT) split injection, with helium as the carrier gas. The methyl esters were separated on a capillary column coated with $70 \%$ cyanopropyl polysilphenylene - siloxane $(10 \mathrm{~m}$ x $0.1 \mathrm{~mm}$ ID- BPX70 $0.2 \mu \mathrm{m}$; SGE, Austin, TX) injector $240{ }^{\circ} \mathrm{C}$ and detector $280^{\circ} \mathrm{C}$. Data was analyzed with the Perkin Elmer Totalchrom Chromatography Software, version 6.2. Heptadecanoic acid (17:0) was added to the samples as an internal standard to correct for recovery and quantitation. Individual fatty acids were identified by comparing their retention with authentic standards (Nu Chek Prep, Elysian, MN).

\section{Data analysis}

Data was analyzed using the JMP 8 analysis software (SAS Institute, Cary, NC). Time-treatment interaction was assessed by two factor Anova. Student's t-test was used to assess significance between the two groups, for each variable and time point (D0 or D90). Paired t-tests were used for assessing significance of change in each group between start and end of study (D0 vs. D90). Because variances were, in most cases, not equal between groups, additional testing was performed. Bivariate analysis was performed for each parameter and group, to determine the dependency relationship between D0 and D90 values. Logistic fit testing was performed on D90/D0 ratios for each parameter and between groups, in order to assess the predictive value of changes for subject classification in either of the treatment groups. For all tests, $\mathrm{p}<0.05$ was considered to declare significance of change.

\section{Results}

In this study 64 parameters were analyzed for potential changes between the group receiving corn oil (C) and the group receiving flaxseed oil (F), for two time points (D0 and D90, Table 3). Preliminary analysis of data revealed that, for many parameters, variances were not equal between groups and, therefore, in such cases, the assumptions for $\mathrm{t}$-testing were not met (data not shown). The unequal variances were present because of the small sample size ( $n=10$ per group) and, for some biochemical parameters, due to the high variability between subjects. In order to determine whether changes between D90 and D0 have predictive value for group assignment, logistic fit was performed using the D90/D0 ratios, calculated as D90/D0 values for each subject. Bivariate analysis was used to determine the correlation degree between D0 and D90 individual values for each treatment group. Table 4 indicates the parameters for which significance (maintenance of correlation between D0 and D90 values) was present in either of the groups, but lost in the other.

\section{MS-related parameters}

Analysis using paired-t tests revealed no changes between groups and time points (data not shown). Analysis of two other related parameters, BMI and insulin concentrations, revealed significant changes when either logistic fit or bivariate analysis was applied. While BMI averages between groups and time points did not indicate significant changes (Figure 1A) the relative BMI ratios (D90/D0) were smaller in the F group $(0.99 \pm 0.01 \mathrm{SE})$ than in the $C$ group $(1.04 \pm 0.03$ $\mathrm{SE}$ ), with significant predictive value (Figure $1 \mathrm{~B}$ ) for group assignment. Serum insulin concentration and the derived HOMA index both 
Citation: Tint D, Anghel M, Lupu DS, Fischer LM, Niculescu MD (2011) Low dose Flaxseed Oil Supplementation Alters the Fatty Acids Profile and the Progression of Metabolic Syndrome in Men without Adequate Medical Treatment. J Nutr Disorders Ther S7:001. doi:10.4172/2161-0509. S7-001

increased in the C group (D90/D0 ratios $2.11 \pm 0.79 \mathrm{SE}$ and $2.00 \pm 0.66$ $\mathrm{SE}$, respectively), while for the $\mathrm{F}$ group both parameters maintained their individual correlation between time points (average D90/ D0 ratio $1.16 \pm 0.20, \mathrm{p}<0.05$, Table 4$)$. The bivariate model for total cholesterol (Col) and triglycerides (TG) associated with MS indicated that, although no statistical significance was achieved for averages between groups, correlation between individual D90 and D0 values were maintained only for the $\mathrm{C}$ group, while the $\mathrm{F}$ group registered loss of correlation (Table 4). Lower ApoA1 D90/D0 ratios were also predictive for the F group, as indicated in Figure 3.

\section{Markers of inflammation}

Among the markers of inflammation indicated in Table 3, flaxseed oil supplementation induced an increase in IL1 $\beta$, while opposite changes were induced by corn oil supplementation (Figure $2 \mathrm{~A}$ ). The D90/D0 ratios $(2.90 \pm 0.80 \mathrm{SE}$ in $\mathrm{F}$ group versus $1.13 \pm 0.17 \mathrm{SE}$ in $\mathrm{C}$ group) also had predictive value for group assignment (Figure 2B). Within the F group, TNFa individual values were correlated between

A)

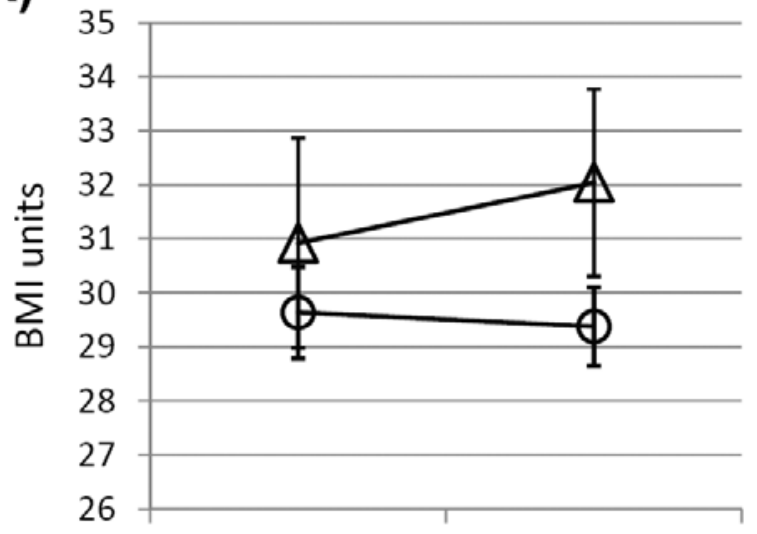

D0 D90

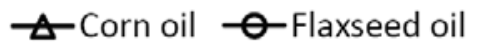

B)

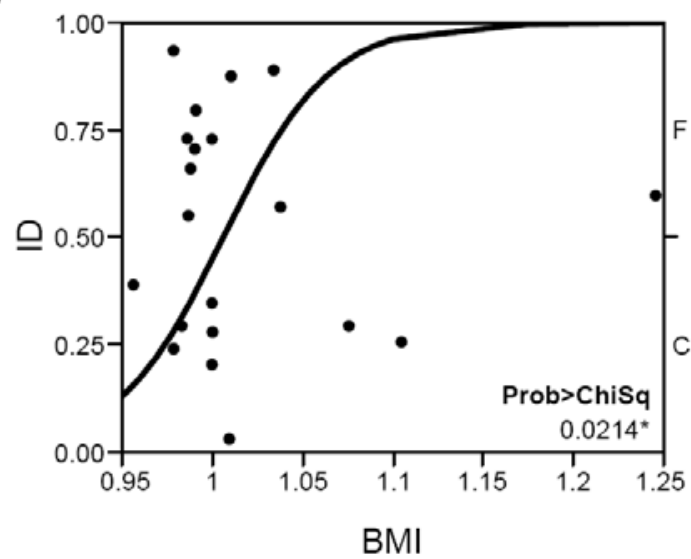

Figure 1: BMI assessment between start and end of study. BMI was assessed at start (day 0, D0) and end of study (day 90, D90) for both groups (flaxseed oil supplementation, F; corn oil supplementation, C). A) Averaged BMI per group is indicated for both time-points, with no significant changes for either group as assessed by paired t-tests. Error bars represent standard error. B) Logistic fit indicated significance for the D90/D0 BMI ratio as a predictor for group classification.
A)

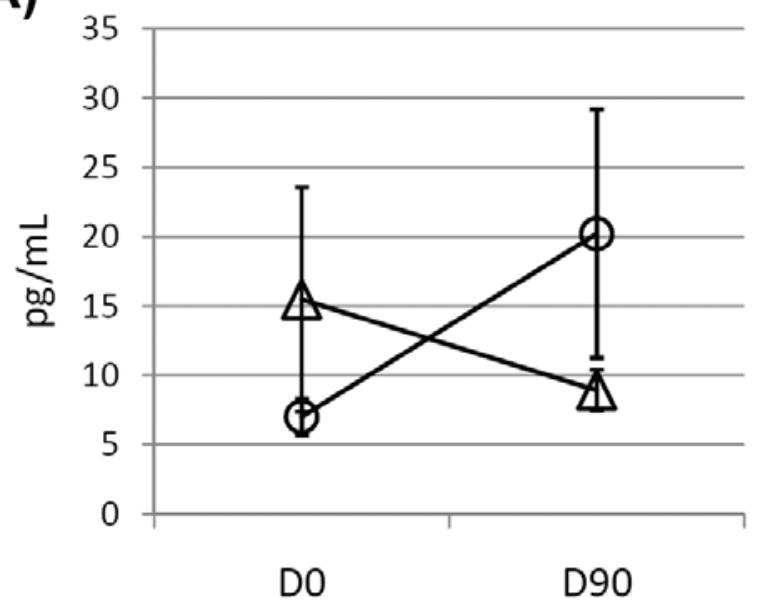

$\triangle$ Corn oil $\_$-Flaxseed oil

B)

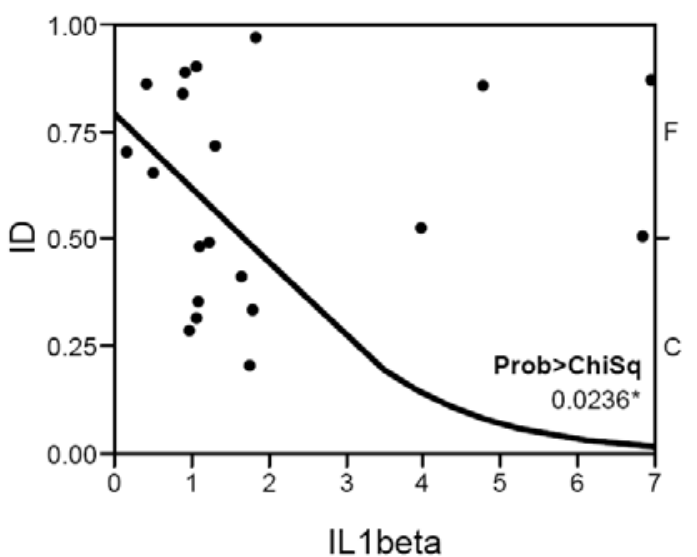

Figure 2: Serum IL1 $\beta$ assessment between start and end of study. Serum IL $1 \beta$ concentrations were measured at start (day $0, D 0$ ) and end of study (day 90, D90) for both groups (flaxseed oil supplementation, F; corn oil supplementation, C). A) Averaged IL $1 \beta$ per group is indicated for both timepoints, with no significant changes for either group as determined by paired t-tests. Error bars represent standard error. B) Logistic fit indicated significance for the D90/D0 IL1 $\beta$ ratio as a predictor for group classification.

D0 and D90 $(\mathrm{p}<0.018)$ while for the $\mathrm{C}$ group the correlation was not present between the same time-points.

\section{Plasma fatty acids composition}

Among the fatty acid species in plasma, $a$-linolenic acid (ALA, $18: 3 \mathrm{n} 3$ ) had lower D90/D0 ratios assigned to the F group as compared to the $\mathrm{C}$ group values $(0.63 \pm 0.11 \mathrm{SE}$ vs $1.25 \pm 0.32 \mathrm{SE}$, respectively, Figure 4). Time-treatment interaction analysis indicated significance for 11-eicosenoic plasma levels (Figure $5 \mathrm{~A}$ ), as determined by the ANOVA-two factor test $(\mathrm{p}<0.05)$. These changes were also significant for group assignment, as indicated by logistical fit analysis of the D90/ D0 ratios, with higher ratios assigned to the $C$ group (1.63 $\pm 0.20 \mathrm{SE})$ when compared to the F group (1.00 $\pm 0.11 \mathrm{SE}$ ) (Figure $5 \mathrm{~B})$. Six other fatty acid species were differently correlated between the two groups, indicating that the low dose of either flaxseed or corn oil could induce specific changes in their plasma profiles (Table 4).

\section{Discussion}

In our study, several parameters were modified by flaxseed oil 
Citation: Tint D, Anghel M, Lupu DS, Fischer LM, Niculescu MD (2011) Low dose Flaxseed Oil Supplementation Alters the Fatty Acids Profile and the Progression of Metabolic Syndrome in Men without Adequate Medical Treatment. J Nutr Disorders Ther S7:001. doi:10.4172/2161-0509. S7-001

Page 5 of 8

\begin{tabular}{|c|c|c|c|c|}
\hline \multirow[b]{2}{*}{ Variable } & \multicolumn{2}{|l|}{ Corn oil } & \multicolumn{2}{|l|}{ Flaxseed oil } \\
\hline & $\begin{array}{l}\mathrm{D} 90 / \mathrm{D} 0 \\
\text { ratio }\end{array}$ & $\begin{array}{l}\text { D90/D0 bivariate } \\
\text { model }(\text { Prob }>\text { F) }\end{array}$ & $\begin{array}{l}\mathrm{D} 90 / \mathrm{DO} \\
\text { ratio }\end{array}$ & $\begin{array}{l}\text { D90/D0 } \\
\text { bivariate } \\
\text { model (Prob } \\
\text { > F) }\end{array}$ \\
\hline AST & $0.90 \pm 0.10$ & NS & $0.84 \pm 0.11$ & 0.0096 \\
\hline ALT & $1.26 \pm 0.35$ & NS & $0.97 \pm 0.14$ & 0.0017 \\
\hline Col & $1.03 \pm 0.04$ & 0.0146 & $0.98 \pm 0.04$ & NS \\
\hline TG & $1.05 \pm 0.10$ & 0.0057 & $0.93 \pm 0.09$ & NS \\
\hline Insulin & $2.11 \pm 0.79$ & NS & $1.12 \pm 0.17$ & 0.0359 \\
\hline HOMA & $2.00 \pm 0.66$ & NS & $1.16 \pm 0.20$ & 0.0243 \\
\hline TNFa & $1.20 \pm 0.70$ & NS & $0.75 \pm 0.19$ & 0.0188 \\
\hline \multicolumn{5}{|c|}{\begin{tabular}{|l|l|} 
Fatty acid species & \\
\end{tabular}} \\
\hline 14:0 (myristic) & $0.94 \pm 0.11$ & NS & $0.99 \pm 0.09$ & 0.0102 \\
\hline 18:0 (stearic) & $1.02 \pm 0.05$ & NS & $0.93 \pm 0.04$ & 0.0489 \\
\hline 18:2n6 (linoleic) & $1.05 \pm 0.07$ & NS & $0.99 \pm 0.04$ & 0.0032 \\
\hline 20:0 (arachidic) & $1.21 \pm 0.21$ & 0.0185 & $1.88 \pm 0.43$ & NS \\
\hline $\begin{array}{l}20: 2 n 6 \\
\text { (eicosadienoic) }\end{array}$ & $1.23 \pm 0.09$ & NS & $1.12 \pm 0.06$ & 0.0034 \\
\hline $\begin{array}{l}\text { 20:3n6 (dihomo- } \\
\text { gamma-linolenic) }\end{array}$ & $1.14 \pm 0.14$ & NS & $1.01 \pm 0.08$ & 0.0258 \\
\hline
\end{tabular}

Linear regression was performed within each group for correlation between time points (D0 and D90). Bivariate analysis was considered significant for $p<0.05$

Table 4: Parameters with significant correlation between time points.

supplementation, as compared with the group receiving corn oil. BMI did not change over the 90 days treatment period in the $\mathrm{F}$ group, while the $\mathrm{C}$ group registered an increase in BMI. Logistic fit of the BMI D90/ D0 ratios indicated that such changes have predictive value for group assignment. Similar predictive values were obtained for changes in IL1beta, ApoA1, ALA, and eicosenoic acid (Figures 1-5).

Bivariate analysis indicated that the flaxseed oil supplementation reduced insulin resistance as assessed by insulin levels and the derived HOMA index. In the F group, the values from D0 did not predict the D90 values, in contrast with the $\mathrm{C}$ group, where the correlation was maintained. TNFa also presented a similar pattern (Table 4).

Surprisingly, lower ALA D90/D0 ratios were assigned to the F group, which could indicate an increase of the ALA desaturation/ elongation rates. However, changes in the levels of other omega- 3 fatty acids were not identified. One could speculate that the amount of ALA received ( $1.2 \mathrm{~g} /$ day) would be insufficient to provide enough substrate for such detectable increases. In addition, the desaturation/elongation of ALA has been reported to be lower in men than in women (reviewed in [17]).

As indicated in Table 2, the major difference in fatty acid composition between corn oil and flaxseed oil supplements, consists of linoleic (LA) and alpha-linolenic (ALA) acids, respectively. Both species had similar molar concentrations (more than $1.6 \mathrm{mmol} /$ $\mathrm{mL}$ ). Therefore, it is not clear whether the observed changes could be assigned to only one of the treatments. However, we may speculate that the flaxseed oil supplementation was favorable against the BMI increase and the increased insulin resistance observed with corn oil supplementation.

While most studies using omega- 3 fatty acids have focused on the effects of EPA and DHA, and upon the role that ALA has in increasing their synthesis, a limited number of studies suggested that ALA may also act as a cell-signaling molecule. In animal and cell culture models ALA has a distinct role in intra-cellular signalling [18-19] and its role in the regulation of gene expression is mediated either through peroxisome proliferator activated receptor (PPAR) -dependent,
PPAR-independent mechanisms (reviewed in [20]), or by altering the phosphorylation of mitogen-activated protein kinases (MAPKs) involved in cell proliferation, differentiation and apoptosis $[19,21]$. ALA inhibits both TNF- $\alpha$ gene expression and NF-kB-dependent transcriptional activity [19]. In our study, TNF- $\alpha$ values were correlated between D0 and D90 in the F group, while corn oil supplementation was associated with a loss of correlation between the same time points (Table 4).

Because it is considered that ALA-derived DHA in humans accounts for less than $1 \%$ (reviewed in [22]), most of the research on $\omega-3$ fatty acids has been focused on dietary interventions using DHA, which is a major component of plasma membranes [22]. Similarly, in animal models, the conversion rate of ALA to DHA in rat brain and liver is less than $1 \%[23,24]$. Moreover, n-3 PUFA deficient diets up-regulate the ALA to DHA conversion [25]. Therefore, there is considerable debate as to whether ALA deficiency reflects into subsequent DHA reduction.

The present study was designed to assess the effect of a low-dose

A)

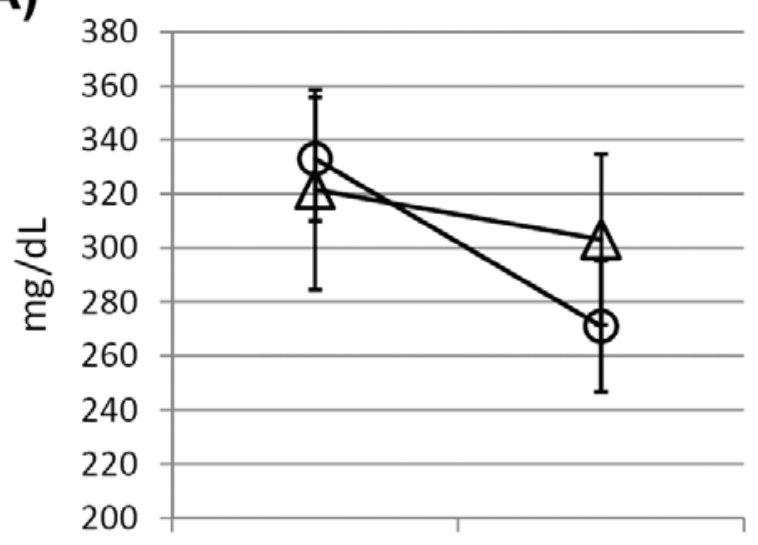

D0 D90

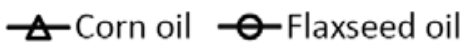

B)

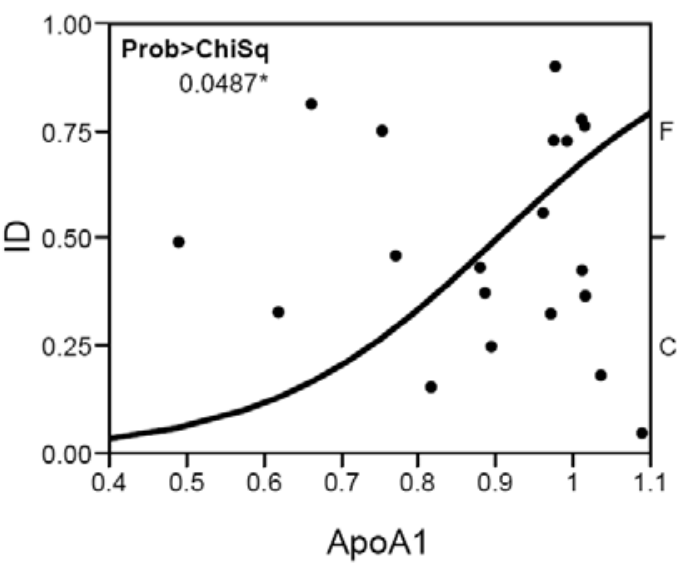

Figure 3: Serum ApoA1 assessment between start and end of study. Serum ApoA1 concentrations were measured at start (day $0, D 0)$ and end of study (day 90, D90) for both groups (flaxseed oil supplementation, F; corn oil supplementation, C). A) ApoA1 group averages are indicated for both timepoints, with no significant changes for either group as determined by paired t-tests. Error bars represent standard error. B) Logistic fit indicated significance for the D90/D0 ApoA1 ratio as a predictor for group classification. 
Citation: Tint D, Anghel M, Lupu DS, Fischer LM, Niculescu MD (2011) Low dose Flaxseed Oil Supplementation Alters the Fatty Acids Profile and the Progression of Metabolic Syndrome in Men without Adequate Medical Treatment. J Nutr Disorders Ther S7:001. doi:10.4172/2161-0509. S7-001

Page 6 of 8

A)

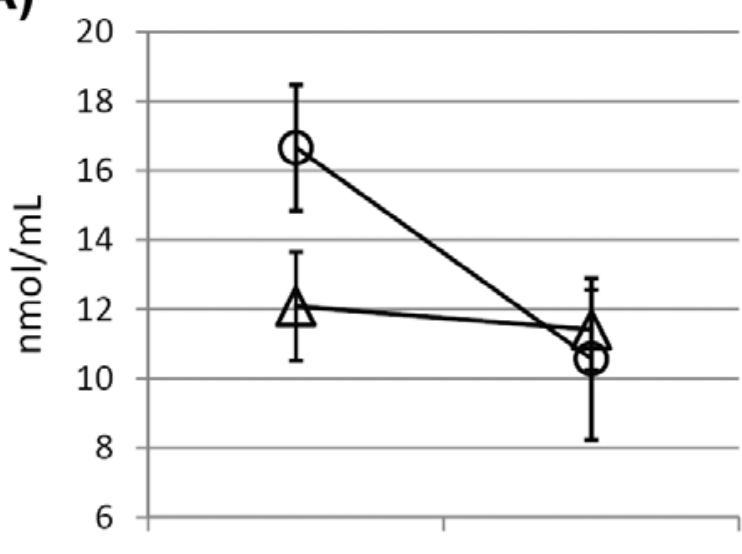

D0

D90

B)
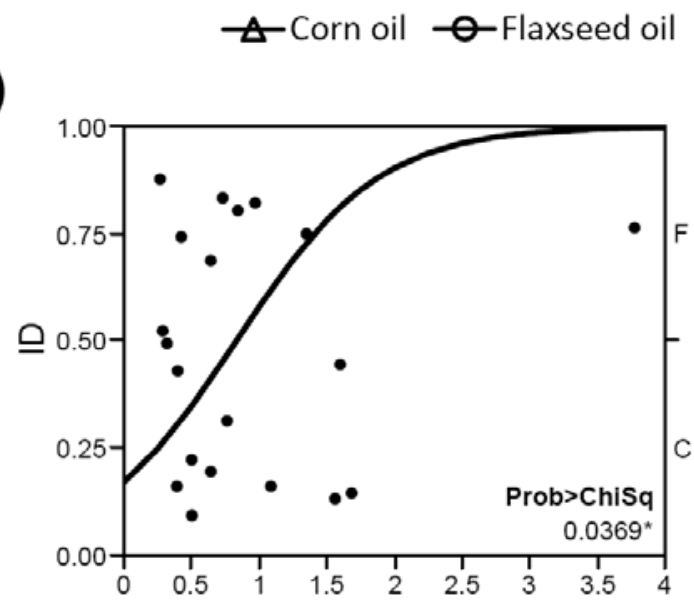

$18: 3$

Figure 4: Plasma ALA levels between start and end of study. Plasma profiles of $\alpha$-linolenic acid (18:3, ALA) were measured at start (day $0, \mathrm{D} 0)$ and end of study (day 90, D90) for both groups (flaxseed oil supplementation, $\mathrm{F}$; corn oil supplementation, C). A) ALA group averages are indicated for both time-points, with no significant changes for either group as determined by paired t-tests. Error bars represent standard error. B) Logistic fit indicated significance for the D90/D0 ALA ratio as a predictor for group classification.

flaxseed oil supplementation in men with metabolic syndrome and it has several particularities. As indicated in Table 2, the flaxseed oil is very rich in ALA (at least 50\%), which is the precursor for EPA and DHA. Our subjects received $2.4 \mathrm{~g}$ flaxseed oil per day, which contained a dose of approximately $1.2 \mathrm{~g}$ ALA. Due to the relative low socio-economic status of this developing country, the Romanian population has, by large, been only weakly exposed to dietary supplements as compared to consumers from developed countries [26]. In addition, the two main types of cooking oils that contain ALA (canola and soybean oil) are not generally used by the majority of Romanians. Therefore, the selection of the study site was designed to include subjects with a lower probability of significant omega-3 fatty acids intakes.

Another particularity of this study is that the subjects did not have access to adequate treatment against MS, largely due to the lack of financial means to procure the prescribed medicine, although they had unrestricted access to medical supervision. With the exception of antihypertensive treatment, these subjects unfortunately were not able to adequately follow the prescribed medication, nor were in the position to follow the dietary recommendations that would include healthier but more expensive foods. Therefore, this study was designed to provide information regarding a less expensive alternative for omega-3 fatty acids consumption.

Previous studies using flaxseed oil supplementation reported discordant results. According to a meta analysis published in 2006, dietary supplementation with ALA was shown to only decrease fasting glucose and fibrinogen concentrations, with no other influence on cardiovascular risk factors (lipid parameters, inflammation markers, systolic or diastolic blood pressure, or BMI) [27]. In relative contrast to our study, ALA administration was ineffective upon glycemic control and insulin resistance in diabetic patients receiving different amounts of ALA [28-30]. Paschos et al indicated that, in subjects with dyslipidemia but no metabolic syndrome, flaxseed oil $(8.1 \mathrm{~g} / \mathrm{d})$ supplementation decreased plasma adiponectin, increased plasma TNF- $\alpha$, and produced a small but significant decrease in serum HDL-

A)

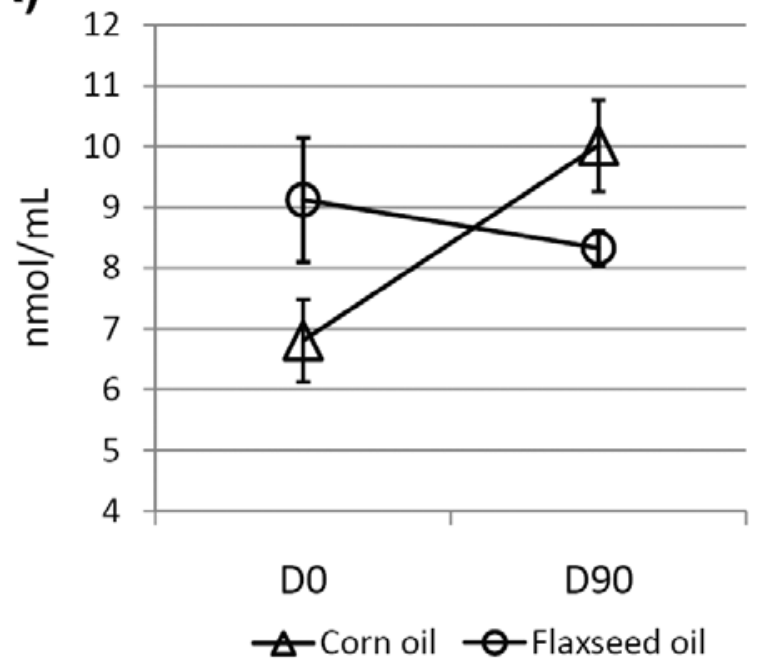

B)

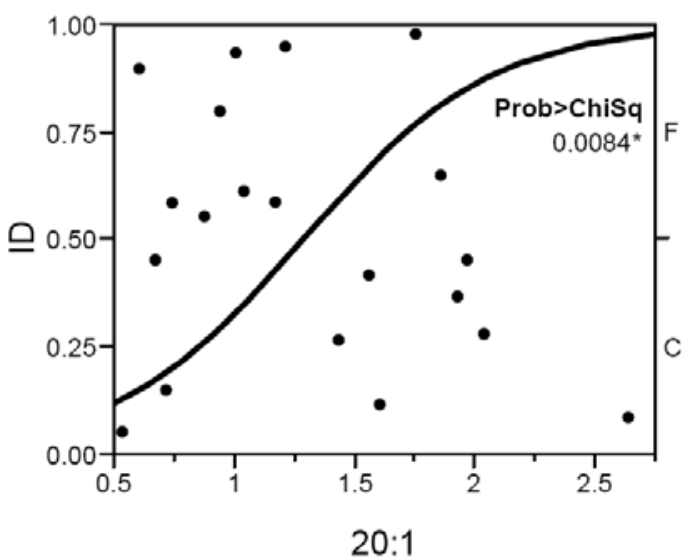

Figure 5: Plasma eicosenoic acid levels between start and end of study. Plasma profiles of eicosenoic acid (20:1) were assayed at start (day 0, D0) and end of study (day 90, D90) for both groups (flaxseed oil supplementation, F; corn oil supplementation, C). A) Eicosenoic acid group averages are indicated for both time-points, with no significant changes for either group as determined by paired t-tests. Significant time-treatment interaction was determined using ANOVA-two factor analysis $(p<0.05)$. Error bars represent standard error. B) Logistic fit indicated significance for the D90/D0 eicosenoic acid ratio as a predictor for group classification. 
Citation: Tint D, Anghel M, Lupu DS, Fischer LM, Niculescu MD (2011) Low dose Flaxseed Oil Supplementation Alters the Fatty Acids Profile and the Progression of Metabolic Syndrome in Men without Adequate Medical Treatment. J Nutr Disorders Ther S7:001. doi:10.4172/2161-0509. S7-001

Page 7 of 8

cholesterol. Other studies in healthy individuals revealed different effects of omega-3 fatty acids administration on lipid parameters, from none to decreased LDL-C and LpA, increased HDL in men, and improved insulin resistance [31-34]. A recent study using flaxseed supplementation reported beneficial effects upon subjects with MS (decreased HOMA), but it was not clear whether the reported results were due to the presence of lignans or ALA, or both [35].

In our study, with the exception of a correlated increase of D90/D0 IL1 $\beta$ ratios within the F group, we found no changes of inflammation markers (averaged values). However, regression analysis revealed that TNF- $\alpha$ was correlated between start and end of study only in the F group. Similarly, insulin sensitivity was correlated in the F group. Our results are in agreement with published studies that have indicated that TNF- $\alpha$ plays an important role in mediating insulin resistance [36]. Increased intakes of dietary ALA demonstrated anti-inflammatory effects by inhibiting IL-6, IL-1, and TNF- $\alpha$ production in cultured peripheral blood mononuclear cells (PBMCs) [37].

An unexpected finding was the significant logistic fit of higher IL1 $\beta$ D90/D0 ratios in the F group. In many studies, MS was associated with increased pro-inflammatory markers, including IL1 $\beta$ (reviewed in [38]), and our results are not in agreement with these findings. However, the roles of IL1 $\beta$ in mediating MS effects, including insulin resistance, are not yet well understood. IL1 $\beta$ genetic polymorphisms were associated with increased risk of MS in subjects with low PUFA levels, suggesting that IL1 $\beta$ loss of function could also increase the risk for MS [39].

The logistic fit analysis indicated that decreased serum ApoA1 D90/D0 ratios are associated with flaxseed oil supplementation (Figure 2). While the ApoB/ApoA1 ratio is the best indicator for MS risk, ApoA1 levels alone are not considered as an adequate indicator for MS assessment [40,41].

The present study has important limitations. The most important factor was the high and unequal variance in data distribution, due to a small sample size in both groups, and to high physiological variations between individuals. As indicated in Table 1, group randomization failed in regard to HDL-cholesterol distribution. Therefore, parametric assumptions for $\mathrm{t}$-testing were frequently not met among the measured variables. While logistic fit or bivariate analyses rendered significance for the discussed variables, it is not clear whether the reported changes have biological significance. We surmise that flaxseed oil supplementation, in opposition to corn oil, was associated primarily with no increase in BMI and insulin resistance, while other reported changes are difficult to interpret in the context of our study design.

Our study aimed to determine whether a low-dose flaxseed oil supplementation regimen could be effective in improving physiological and biochemical parameters associated with metabolic syndrome. Flaxseed oil supplementation associated with no increases in BMI and insulin resistance over a period of 90 days, as opposed to corn oil supplementation. Other alterations were reported for markers of inflammation (TNF- $\alpha$ and IL1 $\beta$ ), apolipoprotein A1, and plasma fatty acid composition. We hypothesize that theses outcomes could be the result of a-linolenic acid supplementation, in accordance with previous similar studies indicating its role in improving insulin sensitivity. However, two notable aspects differentiate our study from previous reports: 1) the enrolled subjects were patients receiving no adequate treatment against metabolic syndrome, and 2) the reported changes were a result of a low dose of flaxseed oil as compared to previous studies.
While the present study suggested that low-dose flaxseed oil supplementation could be beneficial for middle-aged men with untreated metabolic syndrome, more and better controlled studies are necessary to clarify these initial findings.

\section{Competing Interests}

The authors declare that they have no competing interests.

\section{References}

1. Cornier MA, Dabelea D, Hernandez TL, Lindstrom RC, Steig AJ, et al. (2008) The metabolic syndrome. Endocr Rev 29: 777-822.

2. Eckel RH, Grundy SM, Zimmet PZ (2005) The metabolic syndrome. Lancet 365: 1415-1428.

3. Grundy SM, Cleeman JI, Daniels SR, Donato KA, Eckel RH, et al. (2005) Diagnosis and Management of the Metabolic Syndrome An American Heart Association/National Heart, Lung, and Blood Institute Scientific Statement: Executive Summary. Circulation 112: e285-e290.

4. Kelishadi R (2005) Childhood overweight, obesity, and the metabolic syndrome in developing countries. Epidemiol Rev 29: 62-76.

5. Huang T, Bhulaidok S, Cai Z, Xu T, Xu F, et al. (2010) Plasma phospholipids $\mathrm{n}-3$ polyunsaturated fatty acid is associated with metabolic syndrome. Mol Nutr Food Res 54: 1628-35

6. Yashodhara BM, Umakanth S, Pappachan JM, Bhat SK, Kamath R, et al (2009) Omega-3 fatty acids: a comprehensive review of their role in health and disease. Postgrad Med J 85: 84-90.

7. Lombardo YB, Chicco AG (2006) Effects of dietary polyunsaturated n-3 fatty acids on dyslipidemia and insulin resistance in rodents and humans. A review. J Nutr Biochem 17: 1-13.

8. Lombardo YB, Hein G, Chicco A (2007) Metabolic syndrome: effects of n-3 PUFAs on a model of dyslipidemia, insulin resistance and adiposity. Lipids 42 : 427-437.

9. Finnegan YE, Howarth D, Minihane AM, Kew S, Miller GJ, et al. (2003) Plant and marine derived $(n-3)$ polyunsaturated fatty acids do not affect blood coagulation and fibrinolytic factors in moderately hyperlipidemic humans. J Nutr 133: $2210-2213$.

10. Barre DE (2007) The role of consumption of alpha-linolenic, eicosapentaenoic and docosahexaenoic acids in human metabolic syndrome and type 2 diabetes-a mini-review. J Oleo Sci 56: 319-325.

11. Third Report of the National Cholesterol Education Program (NCEP) Expert Panel on Detection, Evaluation, and Treatment of High Blood Cholesterol in Adults (Adult Treatment Panel III) final report. (2002) Circulation 106: 31433421.

12. Simopoulos AP (2009) Omega-6/omega-3 essential fatty acids: biologica effects. World Rev Nutr Diet 99:1-16.

13. Barre DE, Griscti O, Mizier- Barre KA, Hafez K (2005). Flaxeed Oil and Lipoprotein (a) Significantly Increase Bleeding Time in Type 2 Diabetes Patients in Cape Breton, Nova Scotia, Canada. Journal of Oleo Science 54:347-354.

14. Matthews DR, Hosker JP, Rudenski AS, Naylor BA, Treacher DF, et al. (1985) Homeostasis model assessment: insulin resistance and beta-cell function from fasting plasma glucose and insulin concentrations in man. Diabetologia 28 412-419.

15. BLIGH EG, DYER WJ (1959) A rapid method of total lipid extraction and purification. Can J Biochem Physiol 37: 911-917.

16. Tacconi M, Wurtman RJ (1985) Rat brain phosphatidyl-N,Ndimethylethanolamine is rich in polyunsaturated fatty acids. J Neurochem 45 : 805-809.

17. Childs CE, Romeu-Nadal M, Burdge GC, Calder PC (2008) Gender differences in the n-3 fatty acid content of tissues. Proc Nutr Soc 67: 19-27.

18. Darios F, Davletov B (2006) Omega-3 and omega-6 fatty acids stimulate cell membrane expansion by acting on syntaxin 3. Nature 440: 813-817.

19. Ren J, Chung SH (2007) Anti-inflammatory effect of alpha-linolenic acid and its mode of action through the inhibition of nitric oxide production and inducible nitric oxide synthase gene expression via NF-kappaB and mitogen-activated protein kinase pathways. J Agric Food Chem 55: 5073-5080. 
Citation: Tint D, Anghel M, Lupu DS, Fischer LM, Niculescu MD (2011) Low dose Flaxseed Oil Supplementation Alters the Fatty Acids Profile and the Progression of Metabolic Syndrome in Men without Adequate Medical Treatment. J Nutr Disorders Ther S7:001. doi:10.4172/2161-0509. S7-001

Page 8 of 8

20. Innis SM (2003) Perinatal biochemistry and physiology of long-chain polyunsaturated fatty acids. J Pediatr 143: 1-8.

21. Blondeau N, Widmann C, Lazdunski M, Heurteaux C (2001) Blondeau N, Widmann C, Lazdunski M, Heurteaux C. J Neurosci 21: 4668-4677.

22. Innis SM (2007) Fatty acids and early human development. Early Hum Dev 83: $761-766$

23. Scott BL, Bazan NG (1989) Membrane docosahexaenoate is supplied to the developing brain and retina by the liver. Proc Natl Acad Sci U S A 86: 29032907.

24. Igarashi M, Ma K, Chang L, Bell JM, Rapoport SI, et al. Low liver conversion rate of alpha-linolenic to docosahexaenoic acid in awake rats on a highdocosahexaenoate-containing diet. J Lipid Res 47: 1812-22.

25. Igarashi M, DeMar JC Jr, Ma K, Chang L, Bell JM, et al. Upregulated liver conversion of alpha-linolenic acid to docosahexaenoic acid in rats on a 15 week n-3 PUFA-deficient diet. J Lipid Res 48: 152-164.

26. Stefanczyk M (2010) Dietary supplements market in Romania 2010 Development forecasts for 2010-2013. (Publications), Krakow

27. Wendland E, Farmer A, Glasziou P, Neil A (2006) Effect of alpha linolenic acid on cardiovascular risk markers: a systematic review. Heart 92: 166-169.

28. McManus RM, Jumpson J, Finegood DT, Clandinin MT, Ryan EA (1996) A comparison of the effects of $n-3$ fatty acids from linseed oil and fish oil in wellcontrolled type II diabetes. Diabetes Care 19: 463-467.

29. Goh YK, Jumpsen JA, Ryan EA, Clandinin MT (1997) Effect of omega 3 fatty acid on plasma lipids, cholesterol and lipoprotein fatty acid content in NIDDM patients. Diabetologia 40: 45-52.

30. Barre DE, Mizier-Barre KA, Griscti O, Hafez K (2008) High dose flaxseed oil supplementation may affect fasting blood serum glucose management in human type 2 diabetics. J Oleo Sci 57: 269-273.

31. Barceló-Coblijn G, Murphy EJ, Othman R, Moghadasian MH, Kashour T, et al. (2008) Flaxseed oil and fish-oil capsule consumption alters human red blood cell $n-3$ fatty acid composition: a multiple-dosing trial comparing 2 sources of n-3 fatty acid. Am J Clin Nutr 88: 801-809.
32. Bloedon LT, Balikai S, Chittams J, Cunnane SC, Berlin JA et al. (2008) Flaxseed and cardiovascular risk factors: results from a double blind, randomized, controlled clinical trial. J Am Coll Nutr 27: 65-74.

33. Kaul N, Kreml R, Austria JA, Richard MN, Edel AL, et al. (2008) A comparison of fish oil, flaxseed oil and hempseed oil supplementation on selected parameters of cardiovascular health in healthy volunteers. J Am Coll Nutr 27: 51-58.

34. Sioen I, Hacquebard M, Hick G, Maindiaux V, Larondelle Y, et al. (2009) Effect of ALA-enriched food supply on cardiovascular risk factors in males. Lipids 44 603-611.

35. Rhee Y, Brunt A (2011) Flaxseed supplementation improved insulin resistance in obese glucose intolerant people: a randomized crossover design. Nutr J 10: 44.

36. Hotamisligil GS, Shargill NS, Spiegelman BM (1993) Adipose expression of tumor necrosis factor-alpha: direct role in obesity-linked insulin resistance. Science 259: 87-91.

37. Zhao G, Etherton TD, Martin KR, Gillies PJ, West SG, et al. (2007) Dietary alpha-linolenic acid inhibits proinflammatory cytokine production by periphera blood mononuclear cells in hypercholesterolemic subjects. Am J Clin Nutr 85 385-391.

38. Maedler K, Dharmadhikari G, Schumann DM, Størling J (2011) Interleukintargeted therapy for metabolic syndrome and type 2 diabetes. Handb Exp Pharmacol 257-78.

39. Shen J, Arnett DK, Peacock JM, Parnell LD, Kraja A, et al. (2007) Interleukin1beta genetic polymorphisms interact with polyunsaturated fatty acids to modulate risk of the metabolic syndrome. J Nutr 137: 1846-1851.

40. Zhong L, Li Q, Jiang Y, Cheng D, Liu Z, et al. (2010) The ApoB/ApoA1 ratio is associated with metabolic syndrome and its components in a Chinese population. Inflammation 33: 353-358.

41. Pitsavos C, Panagiotakos DB, Skoumas J, Papadimitriou L, Stefanadis C (2008) Risk stratification of apolipoprotein B, apolipoprotein A1, and apolipoprotein $\mathrm{B} / \mathrm{Al}$ ratio on the prevalence of the metabolic syndrome: the ATTICA study. Angiology 59: 335-341.
This article was originally published in a special issue, Nutritional Epidemiology handled by Editor(s). Dr. Ock K. Chun, University of Connecticut USA; Dr. Mihai Niculescu, University of North Carolina, USA 